Boise State University

ScholarWorks

Kinesiology Faculty Publications and Presentations

Department of Kinesiology

$7-1-2008$

Women Bound To Be Active: A Pilot Study to

Explore the Feasibility of an Intervention to Increase Physical Activity and Self-Worth in Women

Jennifer L. Huberty

University of Nebraska at Omaha

Jamie Vener

Southern Oregon University

Cara Sidman

University of North Carolina Wilmington

Jessica Meendering

University of Nebraska at Omaha

Bryan Blissmer

University of Rhode Island

See next page for additional authors

This is an author-produced, peer-reviewed version of this article. The final, definitive version of this document can be found online at Women \& Health, published by Haworth Press. Copyright restrictions may apply. DOI: 10.1080/03630240802132120 
Authors

Jennifer L. Huberty, Jamie Vener, Cara Sidman, Jessica Meendering, Bryan Blissmer, Laura Schulte, Judith A. Flohr, and Lynda B. Ransdell 


\title{
Women Bound To Be Active: A Pilot Study to Explore the Feasibility of an Intervention to Increase Physical Activity and Self- Worth in Women
}

\author{
Jennifer L. Huberty, Ph.D. \\ University of Nebraska \\ Jamie Vener, Ph.D. \\ Southern Oregon University \\ Cara Sidman, Ph.D. \\ University of North Carolina Wilmington \\ Jessica Meendering, Ph.D. \\ University of Nebraska @ Omaha
}

\author{
Bryan Blissmer, Ph.D. \\ University of Rhode Island \\ Laura Schulte, Ph.D. \\ University of Nebraska@ Omaha \\ Judith A. Flohr, Ph.D. \\ James Madison University \\ Lynda B. Ransdell, Ph.D. FACSM \\ Boise State University
}

Keywords: exercise, adherence, self-esteem, female

\begin{abstract}
Increasing physical activity (PA) has become a national health objective due to its associated health benefits, but low participation rates. Therefore, the purpose of this study was to determine the feasibility of an 8-month (September 2006 - April 2007) PA book club (Women Bound to Be Active-WBA) in increasing PA and self-worth (SW) among women. Fifty-six adult women participated in an 8-month intervention consisting of weekly meetings designed to improve PA knowledge, awareness, confidence, and SW. Results indicated a significant increase in PA and SW. The WBA program represents a creative theory-based approach to empowering women to be more active.
\end{abstract}

\section{Introduction}

Due to the substantial role that physical activity (PA) plays in improving health and preventing obesity (Sternfeld, Wang, Quesenberry, Abrams, Everson-Rose, \& Greendale et al., 2004), increasing PA participation is a national health objective (United States Department of Health and Human Services [USDHHS] 2007). However, because the majority of the population is not regularly active (Center for Disease Control[ CDC] 2004), health promotion professionals continue to explore ways to increase PA in this technologically-driven, predominantly sedentary society. Maintaining continued involvement with regular activity is an additional concern because $40-60 \%$ of individuals drop out within the first three months of starting an exercise program (Ainsworth, 2002; Annesi, 2000).

The problem is even more pronounced in women, who are less active than men. Recent statistics published by the Centers for Disease Control and Prevention (2004) indicate that 28\% of women (compared to 22\% of men) reported no leisure time PA. According to the United States Department of Health and Human Services (2004), only four out of ten women are participating in the recommended amount of PA (moderate intensity for 30 minutes on most if not all days of the week or 20 minutes of vigorous activity 3 times per week) (USDHHS, 2004). PA levels also tend to be lower in women with less education, and PA declines as women age (USDHSS, 2004).

Women do not participate in PA for a variety of reasons, including time, motivation, lack of support, lack of resources and other responsibilities (i.e., childcare, cleaning house) (Eyler \& Vest, 2002). Often women spend time in pursuits that are sedentary because they are viewed as more "relaxing" (i.e., television, reading) than participating in PA (Espstein \& Roemmich, 2001; Lee \& King, 2003). For older women, discretionary time is often spent talking on the telephone or reading (Lee \& King, 2003). 
Women who prefer sedentary pursuits need to be motivated to participate in regular PA. White, Ransdell, Vener, \& Flohr (2005) reviewed the research related to women and PA adherence and reported that adherence to PA may be enhanced by cognitive behavior change strategies to overcome barriers, social support including personal contact with a professional, and education. Other factors that may enhance adherence in women include group-based settings and promoting low to moderate intensity levels (to enhance enjoyment) (Fox, Rejeski, \& Gauvin, 2000; Lewis, Marcus, Pate, \& Dunn, 2002). Furthermore, lifestyle activity, or activity that is inherently part of daily living (e.g., taking the stairs, walking to the mailbox, carrying the groceries, etc.), has been widely promoted to increase PA participation because it may be easier for a woman to do and may help her to maintain better health (King, Haskell, Young, Oka, \& Stefanick, 1995; Marcus, Williams, Dubbert, Sallis, King, \& Yancey et al., 2006).

A recent study by White and colleagues (in press) used qualitative methods to examine the predictors of women's continued activity one to three years after completion of a 12-week structured exercise program. Women who remained active reported doing so for reasons related to their self-worth (SW). They felt that they deserved to be active and healthy and reported valuing themselves and their quality of life more than other factors (such as weight and appearance change) as reasons to participate in PA. Studies such as this can provide valuable information that can be used to tailor interventions for women, are aimed at increasing PA participation and SW, and teach women to value non-physical aspects of success.

The terms self-esteem and self-worth are often used interchangeably. Both refer to the satisfaction one has with oneself (McAuley, Blissmer, Katula, Duncan, \& Mihalko, 2000; Merriam-Webster Online Dictionary, 2007). For the purpose of this paper, and based on qualitative findings from a study by White and colleagues (in press), the term self-worth will be used. Conceptually the literature supports the link between PA participation and self-worth. Sonstroem and Morgan's (1989) exercise self-esteem model posits that engaging in regular activity can enhance physical self-perception and ultimately physical self-worth. Empirical studies have found consistent support for the proposed relationships, with changes in PA related to changes in self-esteem, particularly in the physical subdomains (Hickman, Lee, Sallis, Castro, \& Chen, 2004; McAuley, Mihalko, \& Bane, 1997; McAuley \& Blissmer, 2000; McAuley, et al., 2000).

The nature of the results by White and colleagues (in press) and the findings by McAuley and colleagues (2000) suggest the reciprocal nature of self-esteem/self-worth. That is, findings consistently show that having higher perceptions of self-worth/self-esteem are related to greater participation in regular PA and that engaging in activity can foster growth in self-esteem/worth. Therefore, it seems important that exercise interventions strive to foster self- worth as a valuable outcome of an intervention and potential determinant of continued participation.

Book clubs may provide an innovative forum to promote enhanced self-worth and regular PA in women. Book clubs have become quite popular among women, with approximately 500,000 clubs in America today, which is double the number that existed in 1994 (Bryan, 1999). In 1996, Oprah Winfrey announced she wanted to increase the number of readers in the United States and she was able to do this by connecting the readings to life, everyday interests, personal experiences, and concerns (Striphas, 2003). Although empirical studies are still necessary, this and other anecdotal evidence (Rooney, 2003; Striphas, 2003) suggests that the increased awareness that accompanies such thought-provoking readings and discussions may be an effective avenue for facilitating healthy emotional and physical lifestyle changes.

Given the need to develop programs that seek to increase PA and SW, the purpose of this study was to determine the feasibility of a pilot PA book club in increasing PA participation and SW in women. It was hypothesized that PA and SW would increase as a result of participating in this innovative intervention.

The work of McAuley and colleagues on the exercise self-esteem model (McAuley et al., 1997; McAuley et al., 2000) suggests that changes in physical activity and exercise self-efficacy act together to influence changes in selfworth. Therefore, the intervention used proven strategies adapted from both the Transtheoretical Model (stage of change) and the Social Cognitive Theory to enhance physical activity, self-efficacy, and self-worth. Both theories 
have been used to guide interventions for physical activity behaviors in a variety of settings (Dallow \& Anderson, 2003; Pinto, Lynn, Marcus, DePue, \& Geldstein, 2001; Pinto et al., 2002) The specific education/discussion topics and the theory in which they were adapted are listed in Table 1.

[INSERT TABLE I HERE]

\section{Participants \\ Methods}

Inclusion criteria for The Women Bound to Be Active (WBA) intervention were that participants had to be: 1) at least 19 years of age, and 2) in the contemplation or preparation stages of the Transtheoretical Model (stage of change) (Marcus et al., 1992). The pilot study was advertised through a number of venues, including a local internet site promoting PA in the community, flyers posted at local coffee shops, and grocery stores, and through a local newspaper article. Approximately 100 women volunteered for the project. Fifty-five women (46.89 $\pm 11.33 y r s)$ met the inclusion criteria for this Institutional Review Board approved pilot study. Women who replied to the advertisements were questioned to identify their stage of change using the The Physical Activity Stages of Change questionnaire (Donovan, Jones, Holman, \& Corti, 1998; Marcus et al., 1992; Schumann et al., 2003). Participants' answers to four questions related to their current and past engagement in PA categorized them into a specific stage of change. Women who were intending to be active in the next 6 months (contemplation) or irregularly active and/or intending to be active in the next month (preparation) were included in the study. This questionnaire is reliable and valid in adult populations (Marcus et al., 1992).

Women who had questionable health history (chronic disease that the American College of Sports Medicine notes as increased risk for exercise participation (ACSM, 2006), were above 69 years of age, or who answered "yes" to any of the questions on the Physical Activity Readiness Questionnaire (PAR-Q) were asked to obtain a physician's approval prior to participating in the program. All participants completed an informed consent prior to participating in Women Bound to Be Active.

\section{Procedures}

\section{Book Club Description}

Participants paid $\$ 75.00$ to participate in the study to cover the cost of the books and the pedometer. The study was facilitated through a book club that met at three different locations (Southwest, Midtown, and North) in a Midwestern community on different nights during the week and one that was located in a small community in the Eastern part of the United States. Participants could select their location preference. Once a single book club was filled ( $n=20$ per group), women were given the option to join remaining book clubs until the clubs reached their maximum enrollment.

Women Bound to Be Active began in September 2006 and ended in April 2007. At the Midwestern University, book club meetings were facilitated by senior undergraduate or masters Exercise Science and Fitness/Wellness students. All of these facilitators were trained in person by the first author. Facilitators attended the book club sessions led by the first author, and they attended weekly training meetings. For the Eastern University book club, graduate student facilitators listened to an audio file of the book club led by the first author. In addition, these facilitators participated in the weekly training meetings via speaker phone. Two facilitators attended each book club during every meeting to ensure that participant needs were met and adequate notes were kept. Attendance was taken at all meetings. Meetings were one hour in duration and were tapered over eight months with weekly meetings during the first four months and then bi-weekly during the last four months. This tapering methodology was implemented with the intent of developing independent problem solvers who could effectively utilize the learned cognitive strategies.

During the first book club meeting, participants were asked their age; weight was measured to the $0.01 \mathrm{lb}$ using a physician's scale, and height was measured using a tape measure (described below). Physical activity and SW were assessed at baseline and at the end of the intervention (8-months) (also described below). WBA had two phases: cognitive discussions and cognitive discussions plus introductions to different modes of activity. Women were asked to complete questionnaires (described below) prior to the start of the book club. 


\section{WBA Phase 1}

During each WBA meeting, participants shared successes and challenges from the prior week, read material and completed activities designed to improve cognitive strategies, and discussed the weekly book selections. Women Bound to Be Active participants were asked to attend all book club sessions, however, if they missed one, they were still able to participate on their own by reading the current book and completing the cognitive tools in the tool-kit written by the first author. Fiction and non-fiction books were selected by the first author and were included based on their content and relevancy to the following: SW, PA participation and program design, behavior change, modeling (i.e., stories of other women who changed significant health behaviors), wellness, mindfulness, and "women-specific" concerns related to PA or other areas of life. Meetings, discussions, and readings were designed to improve PA knowledge, awareness, confidence, and SW in a group setting.

The goal of the continuous PA education discussions was to educate women about the importance of PA, help women understand the difference between PA and exercise, and teach skills to be active in a variety of settings. For example, participants learned about the FITT principles (Fitness, Intensity, Time, and Type) and how to structure their own personalized program that included cardiovascular, muscular strength and endurance, and flexibility components and could be performed at home or in a gym setting (American College of Sports Medicine [ACSM], 2006). Participants also discussed self-monitoring techniques (e.g., logging, goal setting, etc.) and which techniques were the most effective (Marcus, Forsyth, \& Blair, 2003; Sidman, Corbin, \& LeMasurier, 2004). Finally, women shared their self-reflection from their PA diaries with the group during these discussions.

The goal of the continuous discussions related to SW was to encourage women to value themselves and make themselves a priority so they would make time for PA. Women completed worksheets from their packets to practice a plan for overcoming barriers and setting attainable, realistic goals. Additionally, participants shared how they developed their beliefs about their bodies and their ability to be physically active. Women were challenged to change their perceptions about the reasons they were active. For example, instead of being active to lose weight for a reunion, women discussed how they might think about the impact of increased activity on their ability to carry groceries up stairs or play with their grandchildren without fatigue. Participants were encouraged to address their body appearance and weight from a perspective of quality of life and overall health and wellness (i.e., cholesterol and blood pressure, factors related to cardiovascular disease) rather than those related to weight or a certain clothing size. Further discussion related to self-worth included: 1) exploring ways in which PA was a benefit in their life and how it improved their quality of life, 2) developing strategies to increase their social support networks, 3) understanding the many modes of activity and that it was "ok" to pick an activity that was fun and enjoyable (and if the mode was no longer enjoyable, it was "ok" to pick another mode), and 4) understanding that feeling guilty about taking time for activity did not prepare them for success; it was more desirable to feel that they were worth it and deserve it on a regular basis.

\section{WBA Phase 2}

During phase 2 of the book club meetings, participants were introduced to several modes of PA that were performed as a group during the final 15-20 minutes of each class session. If the discussion topics were not finished, discussion continued along with participation in physical activities. Physical activities were introduced to help the women feel educated and confident about their ability to participate in PA and to help them determine their most enjoyable modes of activity. Examples of activities introduced included walking, low-impact aerobics, and home-based circuit training.

Participants were not given a structured exercise program to follow; they were encouraged to be physically active outside of book club sessions when they were ready. Participants actively engaged in continuous discussions regarding how to use pedometers and how to set attainable, realistic goals for PA participation. It was not mandatory that they attain a specific number of steps or set PA goals related to use of the pedometer. Women were encouraged to engage in PA on their own with the intent that PA participation would increase and be maintained over time. Assessment of maintenance of PA participation following WBA is a planned follow-up investigation after this pilot study. 


\section{Instrumentation}

Health History Questionnaire

A health history questionnaire was used to determine general demographics, medical history, and other health related behaviors. The Physical Activity Readiness Questionnaire (PAR-Q) was used to establish participants' ability to participate in regular exercise (ACSM, 2006).

\section{Weight and Height}

Standardized procedures were used to measure weight and height (ACSM, 2006), and the same facilitator collected data before and after the intervention. Weight and height were used to calculate body mass index (BMI, kg $\mathrm{m}^{2}$ ). Weight was measured on the same physician's scale before and after the intervention.

\section{Objective Measure of Physical Activity - Pedometers}

Digital pedometers (Walk4Life, Inc., Plainfield, Illinois), were used to monitor PA objectively every day for seven months (Sallis, Haskell \& Wood, 1985; Sidman et al., 2004). Prior to use, participants were shown how to properly position the pedometers to ensure accuracy in measuring their PA. If a pedometer was not accurately counting steps or exhibited any malfunction, participants were immediately given a new one. They were asked to record their daily steps from the time they woke up in the morning until the time they went to bed. Participants then submitted their step logs at book club meetings.

\section{Subjective Measure of Physical Activity - 7-day Recall Questionnaire}

Physical activity was assessed subjectively, pre- and post-intervention, using the 7-day Physical Activity Recall Questionnaire. All participants were interviewed and asked to recall PA participation in the morning, afternoon, and evening (moderate, hard, and very hard intensity) during the previous seven days. Acceptable reliability and validity of this instrument has been reported in a number of studies (Gross, Sallis, Budno, Roby, \& Nelson, 1990; Jacobs, Ainsworth, Hartman, \& Leon, 1993; Sallis et al., 1985; Taylor et al., 1984). Validity was established by examining Pearson correlations between accelerometer readings and questionnaires ( $\mathrm{r}=.76$ for sleep, $\mathrm{r}=.56$ for light activity, $\mathrm{r}=.12$ moderate activity, $\mathrm{r}=.31$ hard activity, and $\mathrm{r}=.33$ very hard activity) (Jacobs et al., 1993 ).

\section{Self-Worth/Esteem}

Self-worth was assessed using the Self-Worth Scale of the Adult Self-Perception Profile (Messer \& Harter, 1986). Nine items were included with answers ranging from "really true for me" to "sort of true for me." Examples of items include: "Some adults are very happy being the way they are BUT other adults would like to be different," and, "Some adults sometimes question whether they are a worthwhile person BUT other adults feel that they are a worthwhile person." An individual chooses an answer with which they most identify. Higher scores indicate higher SW. Internal consistency reliability, based on Cronbach's alpha, was acceptable at $\mathrm{r}=.90$ in a sample of women (Messer, 1986).

\section{Data Analysis}

A priori hypothesis were that significant increases would occur in PA and SW; therefore, repeated measures-designs were used. Because this was a pilot study to determine feasibility of the intervention, we used all available eligible participants for the study to determine differences in the outcomes of interest. To assess changes in PA (questionnaire and pedometer results) and SW, repeated-measures t-tests and a repeated-measures analysis of variance were used. Repeated- measures design was used to control for individual differences (each woman was her own control). The most conservative repeated-measures ANOVA was conducted with SPSS using Type III sums of Squares. For the following dependent variables: BMI $\left(\mathrm{kg} / \mathrm{m}^{2}\right)$, weight (lbs), SW (score), and 7-day recall of PA (kcals/day), repeated-measures t-tests were conducted. For the sum of the pedometer readings (average steps/day) from October to March, a repeated-measures analysis of variance was conducted. In addition, effect sizes were calculated for all significant differences using the effect size measure $d$ ( $d=.8$ large, $d=.5$ medium, and $d=.2$ small). 


\section{Participant Attrition}

\section{Results}

Sample size varied across analyses due to inconsistencies with completing all outcome measures. Fifty- five women were eligible to participate, forty-five women volunteered to participate (Table II). Forty-three women participated in at least $50 \%$ of the meetings, and 24 participated in $75 \%$ of the meetings (Figure I).

\section{[INSERT TABLE II ABOUT HERE]}

[INSERT FIGURE I ABOUT HERE]

\section{Weight and Height}

A small but statistically significant decrease in weight was observed in participants of WBA at the end of the eightmonth intervention, $t(37)=2.258, p=.030, d=0.09$. Additionally, a small but significant decrease occurred in body mass index (weight/height ${ }^{2}$ ), $t(37)=2.517, p=.016, d=0.10$.

\section{Physical Activity}

PA (kcals), based on the 7-day recall, significantly increased from baseline to the end of the intervention, $t(33)=-$ 2.887, $p=.007, d=0.21$ (Table III). When PA was measured objectively with a pedometer, a significant increase was also observed (October $=4001 \pm 2,990$ steps, March $=5905 \pm 2,875$ steps), $F(5,135)=4.798, p=.006, d=$ 0.65 , and a moderate effect size.

\section{[INSERT FIGURE II ABOUT HERE]}

\section{Self-Worth}

SW increased significantly from baseline to the end of the intervention, $t(33)=-2.963, p=.006, d=0.45$ (Table III). [INSERT TABLE III ABOUT HERE]

\section{Discussion}

The purpose of this pilot study was to determine the feasibility of a PA book club for increasing PA participation and SW in women. The findings of this study provide preliminary evidence that this innovative approach is feasible in increasing SW and PA among women.

PA levels significantly increased from the beginning to the end of the intervention, as indicated by the 7-day recall and pedometer step counts. Tudor-Locke and Bassett (2004) suggested that taking less than 5,000 steps per day is considered "sedentary" and those participating in 5,000 to 7,499 are considered "low active". Women who participated in WBA increased their activity from low to somewhat active (see Figure II for step counts) according to step count classifications by Tudor-Locke and Bassett (2004). At baseline, participants were taking about 4,000 steps and after the intervention, average steps increased to 5,900, categorizing them as low active. At this low level of baseline activity, any increase in PA is important and potentially health-enhancing (Bravata et al., 2007).

A second important finding was that women who participated in WBA were not asked to participate in any prescribed amount of PA, nor were they asked to participate in a structured exercise program. As previous researchers have suggested, a less-structured, more lifestyle-based approach to promoting PA may improve adherence (Marcus et al., 2006; Dunn et al., 1999). By adding as little as 2,800 to 4,500 steps per day (above what was achieved in the intervention), 3-4 days a week, women who participated in WBA would increase their likelihood of meeting the current public health recommendations for PA (Jordan, Jurca, Tudor-Locke, \& Church, 2005). Since the traditional recommendation of 10,000 steps per day (Hatano, 1993) has been criticized as an unreasonable goal for daily step counts of normally sedentary individuals (Sidman at al., 2004; LeMasurier, Sidman, \& Corbin, 2003; Wilde, Sidman, \& Corbin, 2001), the increase in their physical activity is significant given the baseline inactivity level of these women.

A third important finding was that self-worth increased significantly as a result of participation in WBA. Previous research has focused on the notion that increases in the physical dimension of self-worth facilitate increases in global SW via PA participation and changes in the physical self (e.g., weight, fitness, and appearance) (McAuley et 
al., 1997; McAuley \& Blissmer., 2000; McAuley et al, 2000). It is possible that being a part of a book club, increasing awareness about SW, and spending time with other women discussing topics related to SW caused women to think more about how these elements were important in their lives. It is also possible that learning educational and behavioral strategies that may empower them to be active on their own may increase SW because women felt a sense of accomplishment with learning these new skills. As mentioned earlier, similar strategies have been used in book clubs to provide women with skills and abilities to apply what they are reading to their own lifestyle (in other areas than health) (Striphas, 2003). The differential effects of participation in the book club and PA on changes in self-worth need to be teased apart in future studies through the use of appropriate control/comparison groups and/or studies assessing mediators of changes in PA.

This pilot study illustrates the feasibility of this type of approach (i.e., book club) in empowering women to be physically active. Innovative interventions such as these are feasible in community settings because: 1) they can be implemented through students at local universities (providing students with the ability to use their training and education to offer a service for the community and gain research experience), 2) costs are minimal and limited to books, copy expenses, and pedometers, and 3) WBA teaches skills for women to be active on their own and offers a way for women to participate-- even if they have to miss a book club session by reading material at home and completing cognitive tools in a tool-kit.

While several noteworthy findings were reported, this study had limitations. First, because this was a pilot study, no control group was included. Future studies should include randomization to an intervention and to a control group, an alternative book club control group, or a "traditional" structured exercise group to examine the impact of different aspects of this unique intervention. Second, the attrition rate was fairly high, resulting in a small, homogeneous, and potentially very select sample, thus limiting the interpretation of the findings and restricting their generalizability. Additionally, as the study was designed, participants had to pay for their books and pedometers to participate (\$75). Although this may have limited the participation to women that could afford the fee, a large number of women volunteered for the study (approximately 100) suggesting that some women are interested in participating in this type of intervention who are willing to pay. Although the present 8-month study was longer than many previous studies, it may have been too short to determine the impact of the WBA program on long-term changes in PA and SW. Other methodological limitations included the use of self-report questionnaires, such as the 7-day recall and SW questionnaire which are subject to inherent limitations of self-report formats (Sallis \& Saelens, 2000). However, these self-report tools are widely used and accepted research tools in health promotion. Additionally, an objective measure of PA was used to reduce the limitations of self-reported PA. WBA provides an innovative means for increasing SW and PA in women. Preliminary findings in this study merit continued exploration of this innovative approach with future studies.

\section{Conclusion}

Programs that effectively promote PA adherence in sedentary women are greatly needed. The WBA program presented here represents a creative, proactive approach to PA promotion. The results of this investigation suggest that women who completed WBA significantly increased their PA and SW. Based on these pilot data we speculate that WBA may help change the way women "think" about PA as a result of how they feel about themselves. This could be essential to helping women maintain PA. WBA is a unique, innovative approach to increase SW and potentially increase PA adherence in women. 


\section{REFERENCES}

Ainsworth, B. (2000). Physical activity patterns in women. The Physician and Sports Medicine, 28(10), 2. American College of Sports Medicine (2006). ACSM’s Resource Manual for Guidelines for Exercise Testing and Prescription $7^{\text {th }}$ Edition. Baltimore, MD: Human Kinetics.

Annesi, J.J. (2000). Effects of minimal exercise and cognitive behavior modification on adherence, emotion change, self-image, and physical change in obese women. Perceptual and Motor Skills, 91, 322-336.

Bravata, D.M., Smith-Spangler, C., Sundaram, V., Gienger, A.L., Lin, N., \& Lewis et al.,. (2007). Using pedometers to increase physical activity and improve health: A systematic review. Journal of the American Medical Association, 298(19), 2296-2304.

Bryan, C. (1999). Oprah, just look what you've done!. Library Imagination Paper. 21, 4. Center for Disease Control (2004) The Burden of Chronic Diseases and Their Risk Factors: National and State Perspectives. Retrieved December 1, 2006. http://www.cdc.gov/nccdphp/burdenbook2004/pdf/

Dallow, C.B. \& Anderson, J. (2003). Using self-efficacy and a Transtheoretical Model to develop a physical activity intervention for obese women. American Journal of Health Promotion, 17(6), 373-381.

Donovan, R.J,, Jones, S., Holman, C.D., \& Corti, B. (1998). Assessing the reliability of a stage of change scale. Health Education Research, 13(2), 285-91.

Dunn, A.L., Marcus, B.H., Kampert, J.B., Garcia, M.E., Kohl, H.W.3 ${ }^{\text {rd }}$, \& Blair, S.N. (1999). Comparison of lifestyle and structured interventions to increase physical activity and cardiorespiratory fitness: a randomized trial. Journal of American Medical Association.281(4). 327-34.

Epstein, L.H. \& Roemminch, J.N. (2001). Reducing sedentary behavior: role in modifying physical activity. Exercise and Sports Science Reviews, 29(3), 103-108.

Eyler, A.A., \& Vest, J.R. (2002). Environmental, policy, and cultural factors related to physical activity in a diverse sample of women: The women's cardiovascular health network project. Women and Health, 36(2), 1-15.

Fox, L.D., Rejeski, W.J., \& Gauvin, L. (2000). Effects of leadership style and group dynamics on enjoyment of physical activity. American Journal of Health Promotion, 14(5), 277-83. 
Gross, L.D., Sallis, J.F., Budno, M.J., Roby, J.J., \& Nelson, J.A. (1990) Reliability of interviewers using the 7-day physical activity recall. Research Quarterly for Exercise and Sport, 61, 321-325

Hatano, Y. (1993). Use of the pedometer for promoting daily walking exercise.International Council for Health, Physical Education, and Recreation, 29, 4-8.

Hickman, S.A., Lee, R.E., Sallis, J.F., Castro, C.M., \& Chen, A.H. (2004). The association of physical activity change with self-esteem in ethnic minority women: a prospective analysis. Journal of Gender, Culture, and Health, 4, 281-292.

Jacobs, D.R., Ainsworth, B., Hartman, T.J., \& Leon, A.S. (1993). A simultaneous evaluation of 10 commonly used physical activity questionnaires. Medicine and Science in Sports and Exercise, 25, 81-91.

Jordan, A.N., Jurca, G.M., Tudor-Locke, C. \& Church, T.S. (2005). Pedometer indices for weekly activity physical activity recommendations in postmenopausal women. Medicine and Science in Sports and Exercise, 37(9), 1627-1635.

King, A.C., Haskell, W.L., Young, D.R., Oka, R.K., \& Stefanick, M.L. (1995). Long-term effects of varying aged intensities and formats on physical activity on participation rates, fitness, and lipoproteins in men and women50 to 65 years. Circulation, 91, 25962604.

Le, R.E., \& King, A.C. (2003). Discretionary time among older adults: How do physical activity promotion interventions affect sedentary and active behaviors? Annals of Behavioral Medicine, 25(2), 112-9.

LeMasurier, G.C., Sidman, C.L., \& Corbin, C.B. (2003). Accumulating 10,000 steps: does this meet current physical activity guidelines? Research Quarterly Exercise Sport, 74(4), 389-94.

Lewis, Marcus, B.H., Pate, R., \& Dunn, A. (2002). Psychosocial mediators of physical activity among adults and children. American Journal of Preventive Medicine, 23(26-35.)

Marcus, B.H., Forsyth, L.H., \& Blair, S. (2003). Motivating people to be physically active. Champaign, IL:Human Kinetics.

Marcus, B.H., Rossi, J.S., Selby, V.C., Niaura, R.S., \& Abrams, D.B. (1992). The stages and processes of exercise adoption and maintenance in a worksite sample. Health Psychology, 11(6), 386-395. 
Marcus, B.H., Williams, D.M., Dubbert, P.M., Sallis, J.F., King, A.C., Yancey, A.K., et al., American Heart Association Council on Nutrition, Physical Activity and Metabolism (Subcommittee on Physical Activity), American Heart Association Council on Cardiovascular Disease in the Young, Interdisciplinary Working Group on Quality of Care and Outcomes Research (2006). Physical activity intervention studies: what we know and what we need to know: a scientific statement from the American Heart Association Council on Nutrition, Physical Activity, and Metabolism (Subcommittee on Physical Activity): Council on Cardiovascular Disease in the Young: and the Interdisciplinary Working Group on Quality of Care and Outcomes Research.Circulation, 114(24), 2739-42.

McAuley, E., Mihalko, S.L, \& Bane, S.M. (1997). Exercise and self-esteem in middle-aged adults: Multidimensional relationships and physical fitness and self-efficacy influences. Journal of Behavioral Medicine, 20(1), 67-83.

McAuley, E. \& Blissmer, B. (2000). Self-efficacy determinants and consequences of physical activity. Exercise and Sport Science Reviews, 28(2), 85-8.

McAuley, E., Blissmer, B., Katula, J., Duncan, T.E., \& Mihalko, S.L. (2000) Physical activity, self-esteem, and selfefficacy relationships in older adults: a randomized controlled trial. Annals of Behavioral Medicine, 22(2), 131-9.

Merriam-Webster Online dictionary. (2007). Definition of self-esteem. Retrieved October 18, 2007. http://www.merrima-webster.com/dictionary/self-esteem

Messer, B., \& Harter, S. V. (1986). Manual for the adult self-perception profile. Denver: University of Denver Press.

Messer, B. (1986). The adult self-perception profile: Development, validation, and comparisons of men and women. Dissertation Abstracts International, 47(3B), 1296-1297.

Pinto, B.M, Friedman, R., Marcus, B.H., Kelley, H., Tennstedt, S., \& Gillman, M.W. (2002). Effects of a computerbased, telephone-counseling system on physical activity. American Journal Preventive Medicine, 23(2), 113-120. 
Pinto, B.M., Lynn, H., Marcus, B.H., DePue, J., \& Goldstein, M.G. (2001). Physician-based activity counseling: intervention effects on mediators of motivational readiness for physical activity. Annals of Behavioral Medicine, 23(1), 2-10.

Rooney, K. (2005). Reading with Oprah: The book club that changed America. The University of Arkansas Press. Fayeteville, AK.

Sallis, J.F., Haskell, W.L., \& Wood, P.D. (1985). Physical activity assessment methodology in the Five-City Project. American Journal of Epidemiology, 121, 91-106.

Sallis, J.F., \& Saelens, B.E. (2000) Assessment of physical activity by self-report: Status, limitations, and future directions. Research Quarterly in Exercise and Sport, 71(2), S1-S14.

Schumann, A., Estabrooks, P.A., Nigg, C.R., \& Hill, J. (2003). Validation of the stages of change with mild, moderate, and strenuous physical activity behavior, intentions, and self-efficacy. International Journal of Sports Medicine, 24(5), 363-5.

Sidman, C.L., Corbin, C.B., \& LeMasurier, M.G. (2004). Promoting physical activity among sedentary women using pedometers. Research Quarterly for Exercise \& Sport, 75(2), $\quad$ 122-129.

Sonstroem, R.J., \& Morgan, W.P. (1989). Exercise and self-esteem: rationale and model. Medicine and Science in Sports and Exercise, 21(3), 329-337.

Sternfeld, B., Wang, H., Quesenberry, C.P., Abrams, B., Everson-Rose, S.A., \& Greendale, G.A., et al. (2004). Physical activity and changes in weight and waist circumference in midlife women: Findings from the study of women's health across the nation. 160(9), 912-922.

Striphas, T. (2003). A dialectic with the everyday: Communication and cultural politics on Oprah Winfrey's book club. Critical Studies in Media Communication, 20(3), 295-316. Taylor, C.B., Coffey, T., Berra, K., Iaffaldano, R., Casey, K., \& Haskell, W.L. (1984) Seven-day activity and self-report compared to a direct measure of physical activity. American Journal of Epidemiology, 120, 818-824.

Tudor-Locke, C., \& Bassett, D.R., Jr. (2004). How Many Steps/Day Are Enough?Preliminary Pedometer Indices for Public Health. Sports Medicine, 34(1),1-8. 
United States Department of Health and Human Services. (2004). Steps to Healthier Women: Office on Women’s health 2004. Retrieved November 1, 2006. http://womenshealth/gov/pub/steps/Physical\%20Activity.htm United States Department of Health and Human Services. (2007, January). Healthy People 2010. Retrieved April 8, 2007. http://www.cdc.gov/nchs/about/otheract/hpdata2010/abouthp.htm

White, J.L., Ransdell, L.B., Vener, J., \& Flohr, J.A. (2005). Factors related to physical activity adherence in women: Review and suggestions for future research. Women \& Health, $\quad$ 41(4), 123-148.

White, J.L., Ransdell, L., Sidman, C., Flohr, J., Shultz, B., \& Grosshans, et al. (In Press). Explaining long-term exercise adherence in women who complete a structured exercise program. Research Quarterly for Exercise and Sport.

Wilde, B.E., Sidman, C.L., \& Corbin, C.B. (2001) A 10,000 step count as a physical activity target for sedentary women. Research Quarterly for Exercise and Sport, 7(4), 411-4. 
Table I.

Behavorial strategies and theory/constructs used to implement intervention

\begin{tabular}{|c|c|c|}
\hline Meeting & Topic of Discussion & Theory/Construct \\
\hline Month 1 - September & $\begin{array}{l}\text { Introduction } \\
\text { Purpose of Women Bound to Be } \\
\text { Active } \\
\text { Defining exercise \& PA } \\
\text { Physical activity pyramid }\end{array}$ & $\begin{array}{l}\text { Consciousness raising-Stages of } \\
\text { Change (SOC) }\end{array}$ \\
\hline \multirow[t]{4}{*}{ Month 2 - October } & Self-monitoring & $\begin{array}{l}\text { Self-control - Social Cognitive } \\
\text { Theory (SCT) }\end{array}$ \\
\hline & $\begin{array}{l}\text { Finding a technique that is right for } \\
\text { you }\end{array}$ & Self-reevaluation - SOC \\
\hline & $\begin{array}{l}\text { Benefits of PA } \\
\text { Identifying barriers and how to } \\
\text { "bust” barriers }\end{array}$ & $\begin{array}{l}\text { Environmental reevaluation - } \\
\text { SOC } \\
\text { Stimulus Control - SOC } \\
\text { Self-reevaluation - SOC } \\
\text { Dramatic Relief - SOC }\end{array}$ \\
\hline & $\begin{array}{l}\text { Importance of Quality of Life vs. } \\
\text { weight }\end{array}$ & Consciousness raising - SOC \\
\hline Month 3 - November & $\begin{array}{l}\text { Relapse prevention for exercise in } \\
\text { all weather } \\
\text { Writing and signing contracts }\end{array}$ & $\begin{array}{l}\text { Consciousness raising - SOC } \\
\text { Reinforcement Management - } \\
\text { SOC }\end{array}$ \\
\hline Month 4 - December & $\begin{array}{l}\text { How to set goals - process vs. } \\
\text { product goals, motivation, support, } \\
\text { resources, rewards }\end{array}$ & $\begin{array}{l}\text { Self-efficacy -SCT } \\
\text { Reinforcement management - } \\
\text { SOC }\end{array}$ \\
\hline Month 5 - January & $\begin{array}{l}\text { Enjoyment of physical activity } \\
\text { Finding a mode that is fun and } \\
\text { enjoyable }\end{array}$ & $\begin{array}{l}\text { Self-efficacy - SCT } \\
\text { Self-reevaluation - SOC } \\
\text { Environmental reevaluation - } \\
\text { SOC }\end{array}$ \\
\hline Month 6 - February & $\begin{array}{l}\text { Improving self-worth } \\
\text { Prioritizing } \\
\text { Letting go of guilt } \\
\text { Importance of identifying social } \\
\text { support needs and how to ask for } \\
\text { them } \\
\text { Quality of life vs. societal ideals }\end{array}$ & $\begin{array}{l}\text { Self-efficacy - SCT } \\
\text { Self-reevaluation - SOC } \\
\text { Self-reevaluation - SOC } \\
\text { Helping relationships - SOC } \\
\\
\text { Self-reevaluation - SOC } \\
\end{array}$ \\
\hline Month 7 - March & $\begin{array}{l}\text { FITT principles \& How to design } \\
\text { exercise programs }\end{array}$ & Consciousness raising - SOC \\
\hline Month 8-April & $\begin{array}{l}\text { Practicing wellness (all dimensions) } \\
\text { Reviewing relapse prevention } \\
\text { Wrap up }\end{array}$ & $\begin{array}{l}\text { Reinforcement management - } \\
\text { SOC }\end{array}$ \\
\hline
\end{tabular}




\section{Table II.}

\section{Demographics}

Variable

$n$

Age (yrs) mean (SD)

Caucasian (\%)

African

American (\%)

Ethiopian

American (\%)

\section{Eligible}

55

46.89 (11.33)

49

4

2
Volunteered to Participate

45

48.1 (10.8)

41

2

2
Participated in
$75 \%$ of meetings

24

$49.7 \pm(8.8)$

21

1

2
Participated in $50 \%$ of meetings

43

48.9 (.10.6)

39

2

2
Eligible but did not participate

10

44 (12.7)

8

2

0 
Table III.

Means and Standard Deviations for Outcome Variables

$\begin{array}{ccc}\begin{array}{c}\text { 7-Day Recall } \\ \text { (kcals }\end{array} & \begin{array}{c}\text { Pedometer } \\ \text { (steps per day) }\end{array} & \text { SW } \\ \text { expended/day) } & & \text { (score) }\end{array}$

n

34

28

34

Pre-Test

$2651.46 \pm 719.38$

$4001.46 \pm 2989.8$

$2.82 \pm .72$

Post-Test

$2799.26 \pm 720.75$

$5905.42 \pm 2874.86$

$3.13 \pm .61$

ES

.21

.65

.45

$\mathrm{SW}=$ Self-worth - higher score indicates better score (score ranging from 1-4)

$\mathrm{ES}=$ effect size 
Figure I. Attendance Trends

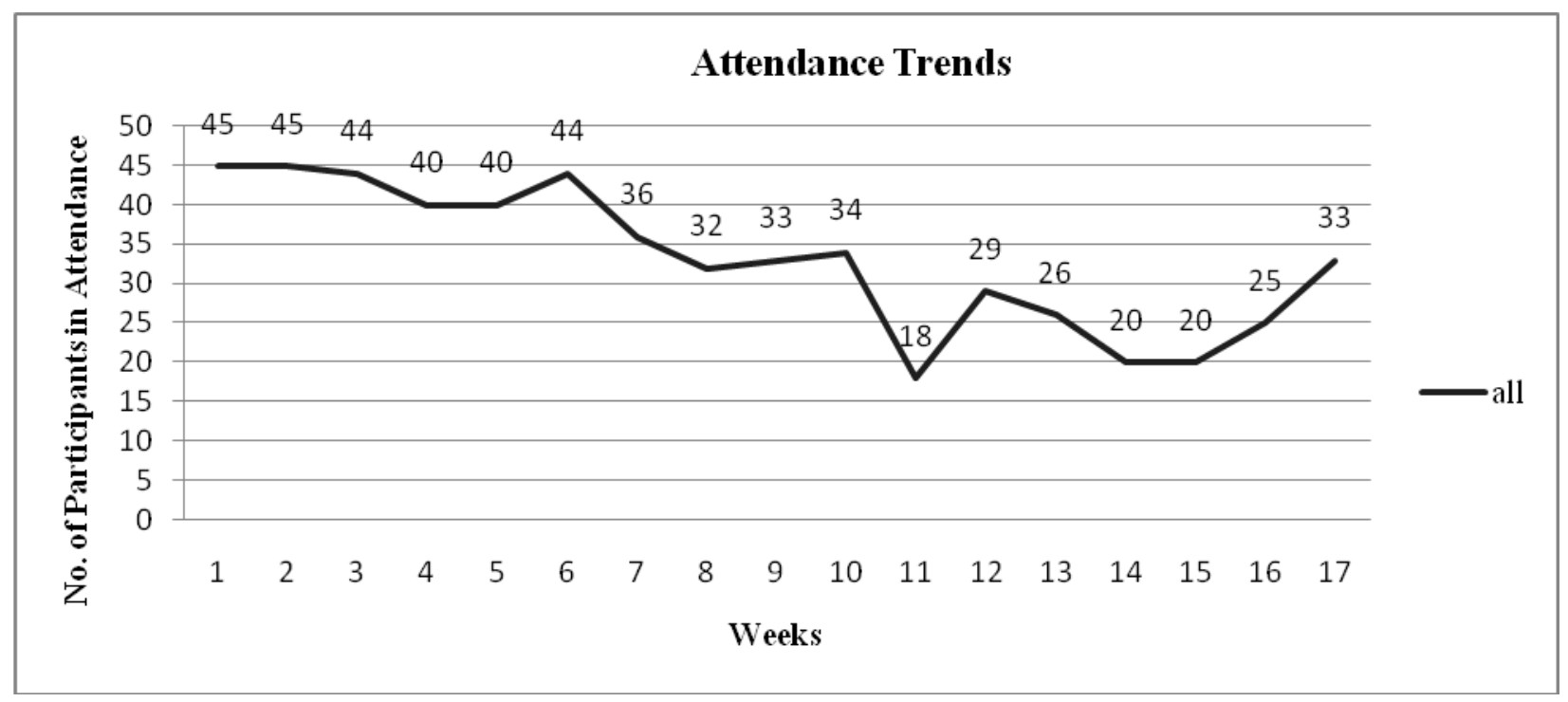

*Note - During week 11, one group did not meet due to severe snow storm. 
This is an author-produced, peer-reviewed version of this article. The final, definitive version of this document can be found online at Women \& Health, published by Haworth Press. Copyright restrictions may apply. DOI: 10.1080/03630240802132120

Figure II. Average daily step counts per month

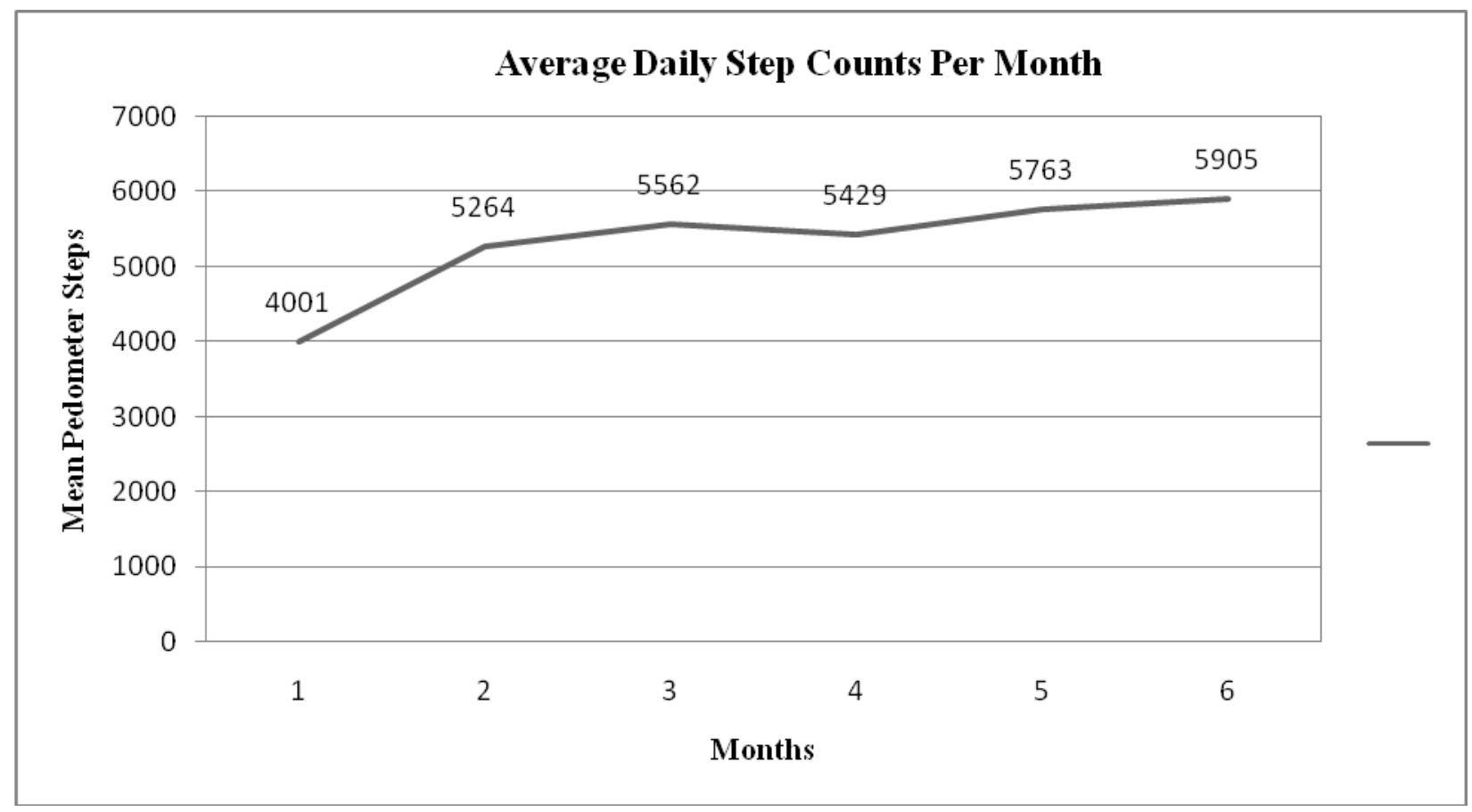

